\title{
DEVELOPMENT OF A TECHNICAL LIBRARY TO SUPPORT COMPUTER SYSTEMS EVALUATION
}

Patricia Munson MALLEY: Librarian, U. S. Army Computer Systems Support and Evaluation Command, Washington, D.C.

This paper reports on the development and growth of the United States Army Computer Systems Support and Evaluation Command (USACSSEC) Technical Reference Library from a collection of miscellaneous documents related to only fifty computer systems to the present collection of approximately 10,000 hardware/software technical documents related to over 200 systems from 70 manufacturers. Special emphasis is given to the evolution of the filing system and retrieval techniques unique to the USACSSEC Technical Reference Library, i.e., computer listings of available documents in various sequences, and development of the cataloging system adaptable to computer technology. It is hoped that this paper will be a contribution toward a standard approach in cataloging ADP collections.

The advent of the computer has created a situation which has been labeled the "information explosion." Through automatic data processing, managers of all types can have available to them information previously impossible. Many authors have addressed this situation from many aspects. However, little has been said of the explosive growth of information about computers themselves and of ways to cope with it. This paper is intended to help overcome this void. It is a description of the system installed by the United States Army Computer Systems Support and Evaluation Command (USACSSEC) to provide controls on its extensive library of technical literature pertaining to Automatic Data Processing Equipment.

The USACSSEC has the mission of selecting and procuring this equipment to satisfy requirements of the Army, a process that involves analyzing and evaluating technical proposals made by computer manufacturers. The analysts of the Command require immediate access to detailed technical literature on all aspects of commercially available ADP hardware and 
software. This literature is maintained in the Command Technical Reference Library. In form it ranges from single-page summaries to multi-volume bound collections. It includes periodicals, books, brochures, and reference works. In approximately five years, the Library's vendor documentation has grown from approximately 200 to 10,000 manuals on over 200 computer systems. The Library's holdings also include information on peripheral equipment from over 170 manufacturers, e.g., printers, magnetic tape transports, microfilm, platters, memories, etc.; standards; GSA Federal Supply Schedules; Programmed Instruction Courses published by vendors; and major reference works with monthly supplements.

In the early days of the Library's existence, one librarian was able to catalog and shelve the material manually with no difficulty. However, the rapid growth in the availability and use of ADP brought with it a flood of technical literature which threatened to inundate the librarian and the manual filing methods. It was recognized early that some form of automation assistance for the Library was necessary. The system described in this paper is the one which evolved and is now successfully employed.

\section{SYSTEM DESCRIPTION}

The system, named ACCESS (Automated Catalog of Computer Equipment and Software Systems), used by the USACSSEC is characterized by simplicity. It is built around a master list of all holdings, and the key to its uniqueness and success is the cataloging scheme.

Manufacturers have various methods of identifying their literature, some having structured stock numbers, some using only the document title, and others ranging between these extremes. The only common identifier is document title, which offers inadequate access to the collection. An efficient cataloging scheme is therefore of primary importance as a means of identifying and retrieving documents.

Searches made by the analysts for whom the library is maintained usually fall into one of three types:

1) Location of a specifically identified document (e.g., the COBOL Programming Manual for the UNIVAC 1108 computer system);

2) Location of all documents pertaining to specific aspects of a particular computer system (e.g., technical descriptions of all output devices for the Burroughs B3500 system);

3) Location of all documents pertaining to particular aspects of a number of different computer systems (e.g., technical descriptions of line printers for IBM System 360, Burroughs B3500, Honeywell 200, RCA Spectra 70, and UNIVAC 1108).

In 1966, since approximately $75 \%$ of the literature in the Library was IBM oriented, IBM's Index of System's Literature, which categorizes documents by subject, was used as an initial model to classify literature of other manufacturers. Since that time a more sophisticated, explicit and expanded subject index has been developed. Table 1 shows a complete list of categories, together with an explanation of them. 


\section{Table 1. Representative Subject Categories and Codes \\ Hardware Categorization}

Subject Code

$\begin{array}{cl}\text { (Tab) } & \text { Abbreviated Title } \\ 00 & \text { General Information }\end{array}$

$01 \quad$ Machine System

03 Input/Output

05 Magnetic Tape Units and Controls

07 Direct Access Storage Units and Controls

08 Analog Equipment

09

\section{Subject Category Content}

Systems summaries, bibliographies, configurators, publications guide, brochures on systems where no technical documentation is provided and price lists not in the GSA Federal Supply Schedule.

EX: Publications guide with addendas.

Principles of operation, operator manuals, operating procedures, reference and system manuals. EX: Processor systems information manual, operating manual. Component descriptions of unit record equipment, e.g., line printers, paper tape readers, card readers, etc.

EX: Printers Reference Manual, Card Punch Style Manual.

Component descriptions and operation of the units.

EX: Magnetic tape unit operating manual.

Component descriptions and operation procedures.

EX: Disc storage subsystem and reference manual.

Information related to analog computers. Also includes the interface equipment for connecting to digital computers. EX: Integrated hybrid subsystem.

Includes plotters, digitizers, optical character readers, all nonstandard I/O devices. Interface equipment.

EX: Graph plotters. 
10

Communications and

Remote Terminal

Equipment

13

15

Physical Planning

Specifications

19

Original Equipment

Manufacturers Information

Component descriptions of communication control devices and remote terminals.

EX: a. Voice response unit.

b. Visual display unit.

c. Teletype, typewriter terminals.

d. Graphic display units.

Special Feature descriptions and Custom Feature descriptions. (Those devices that must be custom built.)

EX: a. Satellite coupler.

b. Programmed peripheral switch.

c. Special feature channelto-channel adapter.

d. European communication line terminal.

Installation and physical planning manuals.

EX: Site preparation and installation manual.

Devices subcontracted from other manufacturers.

EX: Component subleased from one manufacturer for use on own vendors equipment.

\section{Software Categorization}

20 Programming SystemsGeneral

21

Assembler

24

COBOL
General concepts and systems summary related to the software of the system.

EX: a. Catalog of programs.

b. Programmer's guide.

Reference and programming manuals on the assembly language (s) of the system.

EX: a. Assembler language.

b. Card assembler reference manual.

Reference and programming manuals on the COBOL language.

EX: COBOL reference manual. 
FORTRAN

26

Other Languages

Input/Output Control Systems

Data Management Systems

Report Program Generator
Reference and programming manuals on Report Program Generator (RPG) languages. EX: Report program generator reference manual.

Information related to the software facilities for the control and handling of input/output operations.

EX: a. Operating systems basic IOCS.

b. Computer systems input/output package.

Information related to generalized information processing systems which include the functions of information storage, retrieval, organization, etc.

EX: a. IBM - GIS

b. Burroughs - Forge

c. GE - IDS

Standard routines used to assist in the operation of the computer; e.g., a conversion routine, sorting routine or a printout routine.

EX: a. Utility system general information manual.

b. Utility systems programming manual. 

Supervisors-monitors

Automatic Testing Programs

Information related to software facilities whose major functions are to sequence data in a disciplined order according to defined rules.

\section{EX: a. SORT/MERGE Timing Tables. \\ b. General Information SORT / MERGE Rou- tines.}

Information related to techniques, hardware or software, utilized to make one computer operate as nearly as possible like some other computer.

EX: a. Flow simulator information manual.

b. Emulation information manual.

Information related to the programs of a system which are responsible for scheduling, allocating and controlling the system resources and application programs.

EX: a. Disk / Tape operating system operation manual.

b. Operating system programmers.

Interpretive diagnostic techniques which provide analysis of hardware components or of software programs; e.g., hardware autotest programs, software trace routines.

EX: a. Program writing and testing bulletin.

b. System Test Monitor Diagnostic.

Information related to special techniques or application programs.

EX: a. APT General Information Manual. 
Documents are shelved (in loose-leaf notebooks) by manufacturer, computer system, subject category and numerical publication identification. The user is aided in his searches by the following three types of listings of holdings:

1) Listing by manufacturer (Figure 1): major sort field, manufacturer; intermediate sort field, computer system nomenclature; intermediate sort field, subject code (tab); and minor sort field, publication number. That is, a document is listed by publication number, within subject code, within the computer system, within the manufacturer. This list serves as an index to the Library's holdings.

USACSSEC TECHNICAL REFERENCE LIBRARY CATALOG

AS OF JUNE 71

IBM CORPORATION

LIBRARY LISTING BY MFR BY SYSTEM

MRS. MALLEY, LIBRARIAN

\begin{tabular}{|c|c|c|c|c|c|}
\hline IFR & SYSTEM & TAB & $\underline{\text { PUB }} \underline{\text { NO }}$ & PUBLICATION TITLE & $\underline{\text { PUB }}$ DATE \\
\hline & SYS $/ 370$ & 00 & A33-3006-01 & SYS/370 MODEL 135 CONFIGURATOR & 710300 \\
\hline & SYS $/ 370$ & 00 & $\mathrm{~N} 20-0360-71$ & *SRL NEWSLETTER INDEX OF PUBLICATIONS + PROGRAMS & 701231 \\
\hline & SYS $/ 370$ & 01 & A22-6935-00 & SYS/370 MOD 165 FUNCTIONAL CHARACTERISTICS & 700600 \\
\hline$B M$ & SYS $/ 370$ & 01 & A22-6942-00 & SYS/370 MOD 155 FUNCTIONAL CHARACTERISTICS & 700600 \\
\hline & SYS $/ 370$ & 01 & A22-7000-00 & SYS/ 370 PRINCIPLES OF OPERATION & 700600 \\
\hline BM & SYS $/ 370$ & 01 & $\mathrm{C} 20-1729-00$ & A GUIDE TO SYSTEM/370 MODEL 165 & 700600 \\
\hline BMM & SYS $/ 370$ & 01 & $\mathrm{C} 20-1734-00$ & *A GUIDE TO THE IBM SYSTEM/370 MODEL 145 & 700900 \\
\hline IBM & SYS $/ 370$ & 03 & A21-9124-01 & 3505 CARD READER, 3525 CARD PUNCH SUBSYSTEM & 710300 \\
\hline IBM & SYS $/ 370$ & 03 & A24-3550-01 & 3215-1 CONSOLE PRINTER-KEYBOARD COMP DESCR & 700700 \\
\hline IBM & SYS $/ 370$ & 07 & A26-1592-00 & 3830 STG CONTRL / 3330 DISK STORAGE COMP DESC & 700600 \\
\hline IBM & SYS $/ 370$ & 07 & A26-1606-00 & 2319 DISK STORAGE COMPONENT SUMMARY & 700900 \\
\hline IBM & $\mathrm{SYS} / 370$ & 15 & A22-6970-00 & SYSTEM/370 MODEL 155 INSTALLATION MAN PHYS PLAN & 700600 \\
\hline & SYS $/ 370$ & 15 & A22-6971-00 & SYSTEM/ 370 MODEL 165 INSTALLATION MAN PHYS PLAN & 700600 \\
\hline
\end{tabular}

* Indicates new entries since last catalog.

\section{Fig. 1. Sample Index Listing by Manufacturer Name and System.}

2) Listing by subject code (Figure 2): major sort field, subject code (tab); intermediate sort field, manufacturer; and minor sort field, computer system nomenclature. That is, a manual is listed by computer system, within the manufacturer, within the subject code. Within each subject code, or tab, all manuals pertaining to this subject area are listed.

3) Listing by manufacturer name and publication number (Figure 3): major sort field, manufacturer; intermediate sort field, publication number. That is, a document is listed by publication number within the manufacturer. 


\begin{tabular}{|c|c|c|c|c|c|}
\hline$\underline{\text { MFR }}$ & SYSTEM & $\underline{\mathrm{TAB}}$ & $\underline{\text { PUB }} \underline{\text { NO }}$ & PUBLICATION TITLE & $\underline{\text { PUB }} \underline{\text { DATH }}$ \\
\hline $\mathrm{CDC}$ & 6000 & 24 & $60253000 \mathrm{~B}$ & *6000 SERIES COBOL 3 REFERENCE MANUAL & 700700 \\
\hline $\mathrm{CDC}$ & 6000 & 24 & $60191200 \mathrm{~A}$ & 64/65/6600 COBOL REFERENCE MANUAL & 690900 \\
\hline RCA & SPEC70 & 24 & $\mathrm{EC}-001-5-00$ & *ANSI COBOL LANGUAGE TRANSLATOR (UCOLT) PROG PUB & 701200 \\
\hline RCA & 3301 & 24 & 9405000 & REALCOM COBOL & 660500 \\
\hline UNI & 1108 & 24 & FSD 2051 & *FD ANSI COBOL PROG REF MAN & 700504 \\
\hline UNI & 1108 & 24 & UP 7626 R2 & *COBOL EXEC $2 \&$ EXEC 8 SUPPLEMENTARY REF & 700911 \\
\hline UNI & 9200 & 24 & UP 7543 R2 & *COBOL SUPPLEMENTARY REF-SEE 9300-24 & 700511 \\
\hline UNI & 9300 & 24 & UP 7543 R2 & *COBOL SUPPLEMENTARY REF & 700511 \\
\hline UNI & 9300 & 24 & UP 7820 & *9200/9300 COBOL SUMMARY CARD & 700917 \\
\hline UNI & 9400 & 24 & UP $7709 \mathrm{RI}$ & *9400 COBOL SUPPLEMENTARY REF & 700630 \\
\hline UNI & 9400 & 24 & UP 7797 & *9400 COBOL SUMMARY CARD & 700707 \\
\hline $\mathrm{XDS}$ & SIGMA5 & 24 & $901501 \mathrm{~A}$ & COBOL-65 OPERATIONS & 680700 \\
\hline XDS & SIGMA5 & 24 & $901500 \mathrm{~A}$ & COBOL-65 REFERENCE & 680700 \\
\hline
\end{tabular}

Fig. 2. Sample Index Listing by Subject Code (Tab), Manufacturer Name and System.

\begin{tabular}{|c|c|c|c|c|c|}
\hline$\underline{\text { MFR }}$ & SYSTEM & $\underline{\mathrm{TAB}}$ & $\underline{\text { PUB NO }}$ & PUBLICATION TITLE & PUB DATE \\
\hline IBM & SYS $/ 370$ & 01 & A22-6935-00 & SYS/370 MOD 165 FUNCTIONAL CHARACTERSTICS & 700600 \\
\hline IBM & SYS $/ 370$ & 00 & A22-6944-01 & MODEL 195 CONFIGURATOR & 691100 \\
\hline IBM & SYS $/ 370$ & 01 & A22-6962-00 & SYS/370 MOD 155 CHANNEL CHARACTERISTICS & 700600 \\
\hline IBM & SYS $/ 370$ & 15 & A22-6971-00 & SYSTEM/ 370 MODEL 165 INSTALLATION MAN PHYS PLAN & 700600 \\
\hline IBM & SYS $/ 360$ & 19 & A22-6974-00 & SYS/360-370 I/O INTERFACE CHANNEL & 710200 \\
\hline IBM & SYS $/ 370$ & 01 & A22-7000-00 & SYS $/ 370$ PRINCIPLES OF OPERATION & 700600 \\
\hline IBM & 7070,7074 & 01 & A22-7003-06 & $7070 / 7074$ PRINCIPLES OF OPERATION & 620000 \\
\hline IBM & $1401 / 1460$ & 00 & A24-1401-02 & 1401 SYSTEM SUMMARY & 650900 \\
\hline IBM & SYS $/ 370$ & 07 & A26-1606-00 & 2319 DISK STORAGE COMPONENT SUMMARY & 700900 \\
\hline IBM & SYS $/ 370$ & 01 & $\mathrm{C} 20-1738-01$ & A GUIDE TO SYSTEM/ 370 MODEL 135 & 710300 \\
\hline IBM & SYS $/ 370$ & 15 & $\mathrm{C} 22-7004-00$ & SYS /370 INSTALLATION MANUAL - PHYSICAL PLANNING & 710100 \\
\hline IBM & SYS $/ 360$ & 26 & $320-1011-01$ & CALL/360\& PL/1 SUBROUTINE VER 2 & 700200 \\
\hline IBM & SYS $/ 360$ & 25 & $320-1054-00$ & CALL/360 FORTRAN REFERENCE MANUAL & 700200 \\
\hline
\end{tabular}

Figure 3. Sample index listing by manufacturer name and publication number.

\section{Fig. 3. Sample Index Listing by Manufacturer Name and Publication Number.}


The manufacturer needs only to list his documents pertaining to a proposal and an analyst can find them immediately by using this listing. This listing also aids the manufacturer in updating his documents on file in the Library, as most manufacturers publish their own index of publications in numerical order.

The above lists are generated by sorting and listing a master file. The latter is maintained on magnetic tape and updated with punch cards. Four card formats are employed, one for each of the following: 1) addition of publications, 2) deletion of publications, 3) change of title or date of a publication in the file, and 4) change of other information. Tables 2 through 5 show the format for each type of card. It should be noted that in Table 3, information in columns 1-26 must be identical to that in the entry to be deleted, and that the publication title and publication date are not changed by the card described in Table 5 .

\section{Table 2. Punch Card Format for Addition of a Publication}

\section{Card Columns}

1-3

4-12

13-14

$15-26$

${ }^{\circ} 27$

28-74

$75-80$

\section{Information}

Manufacturer (abbreviated)

System number

Subject code

Publication number

The letter ' $A$ ' (key for adding

a publication)

Publication title

Publication date

\section{Table 3. Punch Card Format for Deletion of a Publication}

Card Columns

1-3

4-12

13-14

$15-26$

*27

\section{Information}

Manufacturer

System number

Subject code

Publication number

The letter ' $D$ ' (key for deleting

a publication)

Table 4. Punch Card Format for Change of Title or Publication Date

Columns

1-3

4-12

13-14

$15-26$

'27

28-74

75-80

\section{Information}

Manufacturer

System number

Subject code

Publication number

The letter ' $C$ '

The new title if applicable

The new publication date if applicable
Remarks

Identical

to

Listing 
Table 5. Punch Card Format for Change of Manufacturer, System, Tab, or Publication

Columns
$1-3$
$4-12$
$13-14$
$15-26$
27
$28-30$
$31-39$
$40-41$
$42-53$

\begin{tabular}{l}
\multicolumn{1}{c}{ Information } \\
Manufacturer \\
System number \\
Subject code \\
Publication number \\
The letter 'X' \\
New manufacturer name \\
New system number \\
New subject code \\
New publication number
\end{tabular}

Remarks

Identical to

Listing

A simple program written in COBOL for the UNIVAC 1108 is used to implement ACCESS. Data Cards are read into memory, and the master tape file is updated. Errors such as "no match" or incorrect format are identified during the update process. The updated master file is sorted to provide the three types of output listings described above.

\section{SYSTEM DEVELOPMENT}

The present system evolved over a five-year period. The initial catalogs were prepared and maintained manually, and some of the better features of the early attempts were carried forward into the automated system. Because of this evolution, it is difficult to determine the actual development cost of ACCESS.

Much of the detailed design was done in connection with development of the computer program. Approximately seven man-months were required for preparation and debugging of the program. During this period, a total of approximately two hours of UNIVAC 1108 system time was required. Negligible time has been spent on program maintenance since installation of ACCESS.

Not unexpectedly the greatest effort was expended in collecting and preparing data for the initial master file. The Library in 1967 contained over 3,000 documents, and a punch card had to be prepared for each. The major ADPE manufacturers cooperated in this undertaking, by providing properly punched cards for individual documents. Cards were prepared by the USACSSEC for documents provided by small manufacturers and for miscellaneous documents in the Library.

The major manufacturers have continued their assistance in maintaining the data base, providing punch cards with all new documents delivered to the Library. Nevertheless, it cannot be stressed too strongly that the updating and maintenance of this library file is a very difficult and tedious task representing the work of a full-time librarian, library assistant and 
clerk. The Library may receive 600 new documents and/or page changes, with or without cards, during a thirty-day period.

The master file is updated and new listings produced every sixty to ninety days. More frequent runs would prove more beneficial to the users and require less manpower on the part of the staff. Each run requires approximately ten minutes of UNIVAC 1108 system time.

It is an interesting fact that communication was a problem during detailed design of ACCESS. ADP system analysts and programmers thought and spoke in terms of codes, fields, sorts and files; the Librarian operated in a context of documents, catalog cards, and indexes. A period of mutual education was necessary before effective communication transpired and the system design progressed.

\section{RESULTS}

The Library today contains almost 10,000 hardware/software equipment documents on over 200 computer systems from 70 manufacturers. The flexibility inherent in ACCESS permitted the Library to absorb this rapid growth with minor perturbation. During one six-month period documents describing the mini-computers of twenty manufacturers were added. The subject codes accommodated all documents, and the only modification required to the system was the addition of codes for these new manufacturers.

The value of ACCESS was demonstrated when IBM and RCA announced the new System 7. Documentation on the available hardware and software was delivered on the day of announcement together with punch cards, and within one week this large addition to the collection was completely integrated into the catalog.

ADPE manufacturers also have benefitted from ACCESS. The Army requires that $\mathrm{ADPE}$ vendors, to be eligible for contracts, must maintain current technical documentation of their proposed systems in the USACSSEC Library. Manufacturers are provided copies of the listings pertaining to their equipment to check for compliance with the requirement. Some manufacturers have even accepted the ACCESS cataloging scheme for use in their own libraries.

ACCESS has met the objectives established for it. Benefitting from the evolutionary nature of the cataloging scheme, the system has required a minimum of modifications to date. None of these has been substantive, falling more in the category of debugging rather than in that of design change.

Although ACCESS was initiated and installed to satisfy the unique requirements of the USACSSEC, it has general application. It brings order to the conglomeration of technical information on ADP systems and equipment. The three listings that it produces become, in effect, axes for the multi-dimensional volume of information. 


\section{CONCLUSION}

The USACSSEC Technical Library is recognized as having the most extensive holdings of ADPE manufacturer's literature in the Washington area. No libraries of equal or greater size are known to exist anywhere.

It was planned initially that only USACSSEC analysts and technicians would have access to the information in the USACSSEC Library. However, the resulting interest of various organizations of the Department of Defense (DOD), and the fact that this collection provided information that was otherwise unavailable, prompted the Command to open the Library to a selected group of DOD users. This initial relaxation has gradually evolved into provision for all government and military personnel receiving prior clearance from Command Headquarters USACSSEC to utilize the Library for research. Unfortunately, because of the type of material collected, the quantity available, and the constant demand, it has not been possible to permit the lending of materials. At present, approximately eighty personnel from other government agencies use the Library each month for research. Some of the agencies use it each month for evaluation and selection of computers. User reaction is amazement that such a collection of ADP materials exists.

It is not unusual for relatively new and thoroughly dynamic fields of interest to progress so rapidly that efforts to document them adequately lag behind the latest developments. The problem is particularly acute in the information processing field, whose large amount of technical literature is of little value without an efficient cataloging system.

USACSSEC has solved some of the information problems in the computer field by examining in detail the special on-the-job requirements of computer system analysts in general. By developing its library in terms of the computer industry, rather than specifically to one Command's requirements, a generalized library system in ADP has evolved. It is hoped that this paper will be a contribution toward a standard approach in cataloging ADP collections and creation of a commonality among ADP technical libraries. 